\title{
Transplanting and Manipulating Context from a Corpus: A Pre-writing Strategy
}

\author{
Mubarak Alkhatnai \\ Department of English Language and Translation, College of Languages and Translation, King Saud University, Saudi \\ Arabia
}

\begin{abstract}
The purpose of this research was to examine the impact of transferring and contriving the perspective and message from a collection of written or spoken text, in the context of teaching English writing as foreign $d$ language. The entire research was conducted with a view to create a writing strategy for use in the popular EFL workbook, New Interchange 3. The research further developed into concept mapping the learners' ability at a pre-writing stage on English as a foreign language (EFL) to generate better argumentative essays. On the basis of the results achieved through analytical and experimental case study, the paper intended to design a course plan for the non-native learners of English in the TEFL Writing classes at the College of Languages and Translation, King Saud University. The paper further evaluated and examined the usefulness of the language tools of corpus, collocation and context as pre-writing strategies. It has been the desired objective of the researcher to observe, analyze, and establish the importance of corpus, collocation and context (C3) as viable pre-writing tools. A case study was conducted to ascertain and present the scientific practicability of the teaching of transferring and manipulating a context as a pre-writing strategy.
\end{abstract}

Index Terms - concept mapping, New Interchange 3, EFL, corpus, collocation, context, learning strategy

\section{INTRODUCTION}

Pre-writing strategies use writing to generate and clarify ideas. While many writers have traditionally created outlines before beginning writing, there are other possible prewriting activities. This research paper is based and developed on a course design the researcher made during the fall semester of 2016 for the TEFL class at the College of Languages and Translation. The researcher was instructed to create a strategy for use in the popular EFL workbook, New Interchange 3. In this paper, however, the same strategy is being used which have been abbreviated as $\mathrm{C} 3$. It is taken beyond what it was originally intended for. In designing the curriculum, this strategy had been tested, as a case study, on a non-native learner of English, and in the process, some hard facts were deduced from the results achieved thereafter about the ineffectiveness of the traditionally prevalent pushed-down curriculum, where language learners are expected to sit quietly while they listen to whole-class instruction or fill in their worksheets. The research also reinforced the viability, in today's demanding language learning atmosphere, of the developmentally appropriate practice where the course designer takes into account those aspects of teaching and learning that change with the age and experience of the learner. Many of the lessons the present researcher learned, though, were not only in what was taught, but how he conducted the study. At several key points, some errors were made in testing methods and it showed in the results. After some reflection, it was felt that the errors were a good learning experience for the researcher, as will be explained later. It was hoped that from the beginning of this venture the researcher would be able to see some kind of result, whether good or bad, from his work.

The name C3 stands for corpus, collocation, and context. This is a linear, step-by-step strategy that is believed to use skills that constantly relate back to a text's topic. The rationales will be detailed later in the paper for each step in C3, but basically this is a process of transplanting context from a text for use in pre-writing strategies. It is hoped that in this process, students will, at a minimum, be able to access schemata that would otherwise be left dormant in writing exercises. However, activities that clarify meaning, give stronger associations to previously known words, and allow for students to generate "new" semantic and syntactic structures hopefully will propel them to explore their writing potential.

In this paper, the researcher will test this process on a fairly advanced student named Terry, a 20-year old whose native language is Chinese. Terry was a registered student in the under-graduate Chinese language and translation course, studying English as a second language. He was asked to read four short stories in total and write summaries for each. For the first two summaries, he was not shown any pre-writing strategies, and was on his own to perform the task. He was then introduced to $\mathrm{C} 3$ and set on task to implement the pre-writing strategies for the last two summarizations.

\section{ReseARCh OBJECTIVE}

From the onset, the researcher wanted to observe three things. First, he wanted to see if C3 increased the amount of writing performed by the participant in a summarizing task. It was the researcher's intention to see if accessing schemata using these steps actually provided more written work. Secondly, he wanted to see if it was possible that by 
doing this study, it might inhibit the learner or be burdensome to them while writing. Although it is hard to document or validate these kinds of affective factors, any kind of distraction initiated by learning something new should be at least noted.

The researcher also wanted to observe any changes in grammar and discourse markers. If in fact Terry changed his writing style, even minimally after learning the strategy, then this could serve as fuel for further research. In short, it was the researcher's objective to analyze the quantity and quality differences in the pre-and post-strategy writing samples.

\section{LITERATURE REVIEW}

There have been various on researches on the role of vocabulary in transferring the context from a text. Recent research has revealed that learners need context to apply vocabulary and even more so to store words. If lexical grouping exercises are used out of context, they could slow down the acquisition of new vocabulary. With regard to the quality of words learned, Carroll and Mordaunt (1991) write, "More effective, less random lists are those developed for indirect presentation in a situational lesson. Such a lesson would gather- with a widely variant degree of glossing- words and phrases relevant to specific people, places, tasks, or social situations" (p.24). Although these authors in their article are referring to the Frontier Method of vocabulary learning, the idea of germaneness in learning still applies. One of the major themes in the process of $\mathrm{C} 3$ is to use and manipulate vocabulary that is relevant to what the topic at-hand.

Elaborating on the use and efficacy of the corpora in teaching pre-writing to L2 learners, Yoon \& Jo (2014) say that studies on students' use of corpora in L2 writing have shown the advantages of corpora not only as a linguistic resource to improve writing abilities but also as a cognitive tool to develop learning skills and strategies. This case study seeks to develop new lines of inquiry by comparing the effectiveness and learning strategy use in corpus-based writing revision. Different effectiveness and learning strategy uses were also observed relative to the corpus use contexts as well as according to student proficiency levels.

A large body of work has demonstrated the benefits of corpus-based activities in second language writing pedagogy (Charles, 2007). Those studies have generally shown the positive effects of corpus use on the development of students' linguistic and rhetorical aspects of L2 pre-writing. Given that the linguistic domain often leaves a major challenge even for advanced L2 writers (Kennedy \& Miceli, 2010), corpus-based learning can provide learners with a valuable resource to deal with prolonged linguistic problems. Many corpus studies in L2 writing have manipulated corpora as resources to provide feedback on learners' writing (Yoon \& Jo, 204). For example, Gilmore (2009) showed how learners are able to integrate corpus observations into the redrafting stage of pre-writing to improve the naturalness of writing.

In more recent studies of indirect corpus use, Boulton (2010) conducted several classified studies to test the effects of corpus in language learning. He was mostly interested in the effectiveness of paper-based corpus materials. He constantly found that indirect corpus outputs were more effective than traditional references such as bilingual dictionaries and grammar manuals. Boulton (2010) argued that printed materials provided the conditions for "individual exploration later on with the accompanying benefits of greater autonomy, learner centeredness, and life-long learning" (p.44).

The studies conducted by Yoon \& Hirvela (2004) demonstrated the potential of corpus use in a wide variety of implementations in writing classes, including students' corpus use to improve their knowledge about common usage patterns of words and to increase confidence in L2 writing enhancing students' awareness of grammatical patterns and rhetorical functions in writing classes.

Regardless of the type of corpus use, this study found that teacher's guidance and scaffolding was crucial in helping to lead learners to successful experiences in corpus analysis. In this sense, we stress that teachers must receive basic training in accessing corpora and evaluating concordances. As Sinclair (2004) noted, "a corpus is not a simple object, and it is just as easy to derive nonsensical conclusions from the evidence as insightful ones" (p.2). When training familiarizes teachers with the corpus-based environment, they can facilitate students' autonomous learning and make them become active language detectives.

Justifying the need of using or manipulating the corpora for teaching writing to L2 learners, Mukherjee (2006) says that the corpus makes it possible to focus on individual learners' inter-language skills and to provide them with spot-on feedback. The corpus can be analyzed both by teachers and by students. For example, individual learners can use a concordance display of their own mistakes as a starting point for data-driven learning activities.

While previous studies have been inconsistent about the relationship between proficiency levels and the effect of corpus use, the present study revealed that corpus-based instruction can benefit different levels of students if we consider their different patterns and strategies relative to the two corpus applications. The indirect use of corpora appeared to have greater effectiveness in error correction and also in raising learning awareness (Bernardini, 2004). If the findings in this research are replicated, then it can reassure teachers with less-endowed technological infrastructures-particularly in developing countries-- that indirect use can still benefit students' linguistic acquisition in L2 pre-writing.

\section{Discussion: Corpus, Collocation, AND CONTEXT}


C3 uses short stories or any corpus, as ready-made context that can be immediately applied to existing vocabulary and pre-writing strategies. It is not the intention of the researcher to reinvent the wheel here, by creating a new set of language learning techniques; as there are plenty of good ones out there. But this research is driven by an empirical observation through the scholarly sound literature reviews and the practical experiments in classroom that this combination of already-used techniques gives this strategy a unique twist. There are links and connections between the given topics of a story and the language used that can serve as a catalyst for generating even more writing tasks.

Before beginning to explain this approach, it is imperative to mention the reasons behind the divergence taken in this paper from the original C3 made in poster form illustrated in the end of this Discussion. Attached to this paper is a picture of the poster and noted below are numbers that correspond with each step highlighted in bold-face type. As this strategy was originally based on an EFL classroom setting, the first step originally was an awareness raising activity. Here, the researcher has skipped that stage and went straight to the reading of the text. In short, it will mean combining steps 2 and 3. Skipping over the awareness-raising activity was partly due to the participant's level of English, the time allotted to do this, and the length of text which was fairly short.

The participant began this strategy by reading the text. After reading, he was instructed to find the main idea of the story. This is an extremely important step, as the whole strategy depends on and uses the topic or main idea. This step need not be thorough, as it is only for the raising of awareness, so only a few words or a sentence need to be written about the main idea. Here, it is important that the learner knows what the text is about, and write it briefly on paper. If the text is too far above the learner's ability in the TL, then it is not assured as to how much benefit this will have as they might be off the mark in comprehending the passage's main idea. As a consequence, selecting materials becomes a thorny issue for instructors. Learner comprehension and managing comprehensible input can be treated in a subsequent paper; here the researcher will focus on learners who are able to manage and comprehend what they are exposed to.

The next task after finding the main idea will be to find single words in the text that give some amount of proof to choosing the main idea, and create a list of these words tasks. If the main idea was for example, about saving whales, then the list one would compile would relate directly to that. The words extracted from the story could be 'ship' or 'mammal', depending on what was discussed in the text. It is important at this juncture that the student realizes that although this is an explicit learning strategy, the compilation of words used should not be isolated from the text. In other words, choosing words out of interest in learning the word would be off track, as a good deal of effort went into bridging and sequencing all steps based on topic.

It is also important to point out the role of student choice in compiling a topically relevant list. In an article about vocabulary generation, Sokmen (1992) states, "When learners are engaged in making sense of the lexicon and are able to expand vocabulary to their own needs, they retain more words" (Sokmen, p.16). Although the topic is what drives the word list, it is still a matter of choice what specific parts of the story the learner wishes to focus on. Referring to choice as a motivating factor, Carroll and Mordaunt (1991) also agree, "Students enjoy the fact that words are student generated rather than given to them as an assignment, thus making the process personal and therefore more meaningful" (p.24). As creativity plays a pertinent part in the mind mapping activity in step 6, its important that the student be able to choose exactly what words they will choose to map out, so that they have a measure of enjoyment and a feeling of responsibility towards their writing.

After the student has generated a list of topically relevant words, using the BBI Dictionary of English Word Combinations (a collocational dictionary), the student finds the word's collocates. It is important to note here that the student should have an awareness of collocations before implementing this strategy. Having a large cache of memorized collocations here however, does not serve the overall goal. When presenting collocations to students, Lewis states, "It must be stressed that the primary purpose of the activities is awareness-raising, rather than formal "teaching'." (Lewis 1997, p.260) In this the researcher deems it necessary to explain what a collocation was to Terry prior to any exposure to C3. It was taken for granted that he understood what a collocation is after being told, however, that this was something that would be addressed in the analysis part of the paper.

Although the participant in this study was not comfortable with the idea of how a collocation really works, Lewis would support the notion that large amounts of knowledge of specific collocations are not absolutely necessary to use them. Concerning this, he says, "One important implication of the arbitrary nature of collocation...It is very much a case of being in 'telling' rather than 'teaching' mode." (Lewis 2000, p.35) This was also part of my explanation to Terry, which was more or less, "just try it", after seeing him struggle with understanding what a collocation is.

The next step was to choose which collocates, if any, are relevant to the topic. In experimenting with how practical this specific exercise may be, the researcher found that although many collocations are absent from the BBI dictionary, it is thorough enough that students will find collocates more often than they wont. It may also be the case that no collocation is relevant to the topic of the reading. If this is so, then the student will need to find a new word. The researcher, however, does not practically consider that the student's discarding of a collocation from their list, even if irrelevant to the story, is a waste of time. Knowing what to exclude from something is in itself, an act of understating the boundaries of what is germane to the topic. It may take more time for the student to go back and choose new words from the text to explore collocations for, but the process of eliminating irrelevant collocations is beneficial at least to a small degree. 
After finding the word in the BBI and listing the relevant collocates, the student chooses a few to work with in a mind mapping-type activity. For this study, the researcher has chosen to limit the amount of collocations used to keep the task manageable for the learner. For example, if the student has a list of 10 relevant words, he might use five or six of them to find collocates, and then narrow that down for the mapping activity. If we were to ask the student to make mind maps for 6 collocations, it could be easily expected that the maps to be scant and lacking creativity. For this research the researcher has decided that two mind maps would suffice for brainstorming on how to summarize a short story.

Using the whole collocation from the BBI, on a separate place on the paper, a mind map is generated. The student is instructed to explore every option a word may present, and detail that in a bubble-type format. It is believed that the semantic value a collocation has, elicits ideas and accesses schemata from the learner in a unique way. For example, using the word 'quiet' for a mind map will evoke certain thoughts and ideas. Using the collocation 'keep quiet', however, contains more linguistic baggage and therefore can elicit more specific and targeted ideas for mind mapping. After seeing this collocated pair, the researcher conjured up ideas about a library and authority and peoples fingers over their lips. This is a bit more specific, as a single word can lead the learner down a path that strays from the main idea. One might think of 'quiet' as referring to nature, whereas 'keep quiet' provokes a more targeted response. It is the aim here that if a student chooses a relevant collocation which refers back to the topic, then there will be a good chance that they will have schemata access in a similar way, which produces more semantic value.

Adaptations to the mind maps could be used, having students not only generate associated words, but also opposites or words that have degrees of value such as 'hot-warm-cold'. The mind mapping activity can be a very creative exercise. A well thought out display of a learner's lexical framework can not only aid the learner, but also the instructor, in seeing not only the amount of words a student knows, but also what they have tendencies to write or think about.

After having a sufficient amount of associations in their map, the student is finally set on task to summarize the story. $\mathrm{He}$ is told to use the mind map as a reference, but to keep in mind that the maps are not the story, and that a summarization of the text is the task-at-hand.

\section{The Study: Methodology - Research Design and Data Collection Procedure}

The study that tested this pre-writing strategy was conducted over two sessions. For these, the researcher selected four texts for Terry to read. He was given no prior instructions other than to summarize for the first two readings, and was shown how to do C3 for the last two readings. The texts used were two American folktales and two short stories written by random authors. For the folktales, he was given 5 minutes to write as much as he could, and for the stories, he was given 7 minutes. Only once during each of the allotted times the researcher gave him a signal as to how much time he had remaining. In this paper, these readings and assignments will be referred to as Tasks 1 through 4 . The folktales were administered first and third and the short stories were second and fourth.

In choosing the texts to read, the researcher wanted to use two different discourse types that had a similar amount of words contained in them. For example, the folktales had roughly the same amount 483 and 274 respectively, while the short stories had 722 and 927 words. This was important in that for the first session, both one folktale and one short story were used, and for the second session, the other folktale and story were used. This amounted to at least a small degree of consistency, given that not too much analysis of the text was taken, aside from discourse type, level, and length. Syntactical structures and grammar issues were not addressed.

The folktale readings were acquired through a link from an ESL website, although apparently they were written for a non-native speaking audience. Barring a few instances of colloquialism found in folklore, they are certainly at a lower level and within reach for the participant. The short stories however were a bit more complicated and had an appeal that a 20 year old might find interesting. For example, the reading for Task 2 was "The Match", a story about a soccer player that holds his shot and mortally wounded brother in his arms. The other short prose was "The Bully", a tale about a man who sees his childhood bully later on in life, in a position of vulnerability. Although it was not recorded, Terry was closely observed as he read each article. He seemed much more interested and involved in the short stories than he did reading about folklore.

The researcher then set out to implement this study by following a series of steps. Initially, the first two summary activities were not given any instruction other than to summarize the passage. During the second meeting between us however, the learner was made aware of the C3 strategy prior to reading. It was quite predictable that after reading the text, the learner should be put on task to use the strategy, as the reading is fresh in his mind. The opposite would be to read, and then stop to learn about C3, and then go back to use the text in a summarizing activity. This approach seemed a bit disjointed, so the researcher opted for the latter.

Since this was a new strategy for Terry and given that the researcher gave him minimal assistance during his first run-through with the process. For example, Terry was watched as he chose a collocation and answered a couple of questions. The specific collocation that he chose to mind map was thus noted down, thus showing him how to make use of the space left on the paper. Here it is not necessary to look further into what kind of impact, if any, this may have had since it did not take any of the burden or responsibility off of him.

Picture of the poster form: 


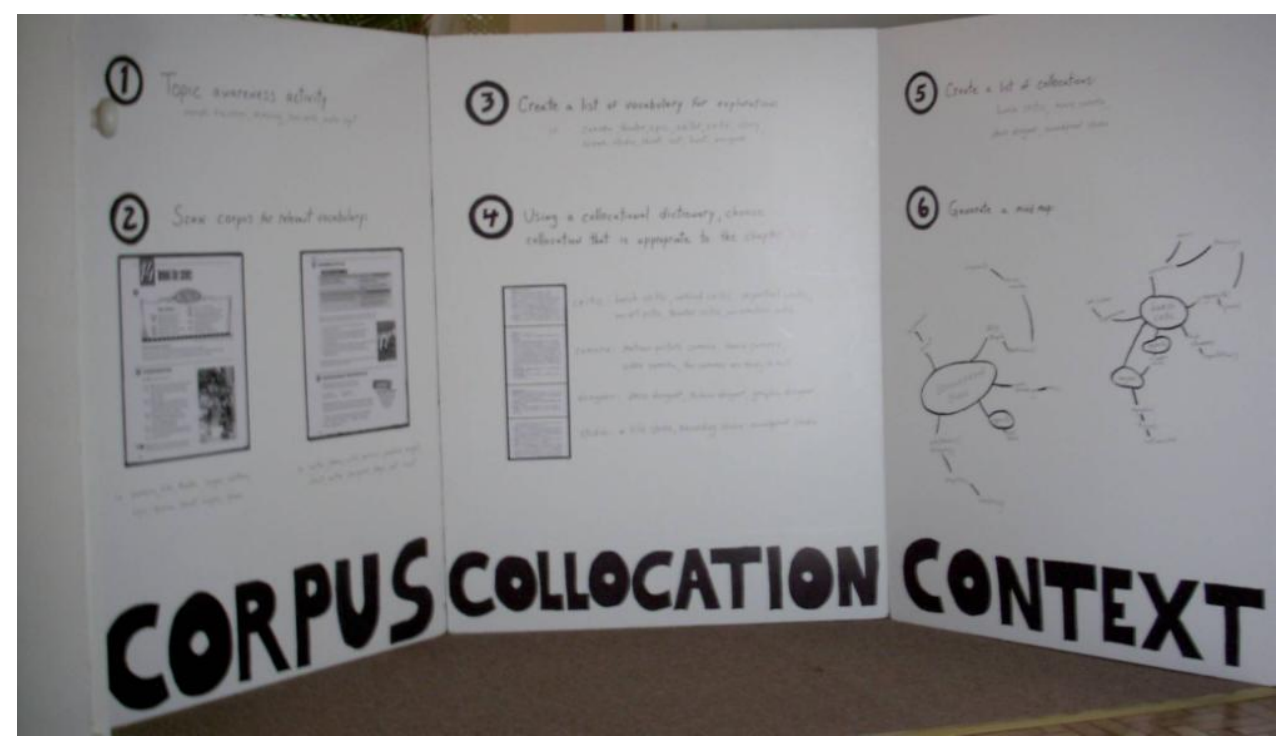

\section{Empirical Results}

Below is a chart that details some of the information that I acquired from Terry's writing:

A- \# of words in the reading

B- \# of words written in the summary

C- \# of sentences written in the summary

D- average \# of words per sentence in the summary

\begin{tabular}{|l|l|l|l|l|}
\hline & A & B & C & D \\
\hline Task 1 & 483 & 99 & 8 & 12.3 \\
\hline Task 2 & 722 & 107 & 10 & 10.7 \\
\hline Task 3 & 274 & 92 & 7 & 13.1 \\
\hline Task 4 & 927 & 113 & 14.1 \\
\hline
\end{tabular}

A salient feature of Terry's writing was that there was hardly any difference in the amount of words produced on each day. For example, in Tasks $1+2$ on the first day, he produced 206 words total. In Tasks $3+4$ following the first session, he produced 205 words. It is observed that this is an exceptionally close number and was a bit shocked when the totals were calculated.

Terry also kept the summaries fairly consistent in length when comparing the two different reading types assigned. For the Tasks that involved American folklore, the total words produced were 99 and 92 respectively, and for the short story tasks, the numbers were 107 and 113. Although these numbers are a bit different, the difference between them is but the completion of a sentence or two.

What was puzzling though was that the amount of information between the two discourse types was considerably unbalanced. For example, the folklore texts had a total of 757 words, while the short stories contained 1649 words. Since the number in the second group was more than double the first, it would seem to follow that there would be more to write about. The researcher had also assumed that because the prose had more situations that required inference that it would contribute to more schemata access. In addition, there was also more time to write for the short story summary task. This was startling for me because the writing had relatively similar amounts of words in light of the huge gap in length of provided text.

There was also a trend in the manner in which he began his summarizations. Beginning sentences in Tasks 1, 2, and 4 started out, "This story is talking about..." and in the third task, the opening line is, "It's about a great driller." From this, it seems that Terry is following some kind of writing convention. Although that is painfully obvious to point out, its is important in that it may give clues to affective factors such as a priori writing experiences, boredom, or a lack of desire to give real introspection to the writing assignment. More likely, in my opinion, is that when asked to perform a summary, he reverts back to his L1 writing conventions. This may be the case, although the researcher is not familiar with Chinese writing. However from the researcher's experiences with Asian students, regurgitation of information is the norm for many writing assignments.

Lastly, it is important to make a note that although it is difficult for to label with precision the collocations in Terry's writing, the researcher did go through the summaries and list the collocations he wrote, and it was discovered that this was the only representation where teaching C3 had any effect. In summaries 1 and 2 there were 3 collocations in his work. It is noteworthy that the researcher didn't include "fall down on his knees" and "good friend in the world" from Tasks 1 and 2. It was included because in a chunk of meaning, if one part is wrong then collocate is certainly off base. As they are chunks, they need to retain their semantic as well as syntactic values. 
In the third and fourth Tasks, a total of 9 collocations were found. In Task 3, however one of the collocations that was tallied was taken from his list in step 5 of the C3 process, which was though written down, but Terry had already acquired it from the BBI. This was interesting to because in Task 3 Terry was given a minimal assistance with the steps leading up to the mind map. In light of that, he really only produced on his own, 3 collocations, whereas in the fourth Task, he came up with 5. Why this is relevant is that even when he produced more collocations, yet in the fourth Task, he failed to use the proper procedures, which entailed transplanting the collocations from his collocate list to the mind map. His mind maps were just the words 'friend' and 'love' in Task 4, and he produced more collocations in that summary than the rest. There is a possibility that just the exposure to collocations lowered some of the affective filters and allowed him to relax his English usage and use more colloquial terminology.

\section{STATEMENT OF Limitations}

One of the dilemmas for this project was the skimming and scanning aspect of reading. Originally C3 was intended to use skimming for main idea, and then scanning to get words that fit the topic. Then only after that, is the student set on task to read. This would be effective for a comprehension type-activity and I wrestled with the choice of having Terry skim and scan before he reads, or read then skim and scan.

As a proper ode of research, scrutiny, and analysis it was needed to research as to how summarizations work, which would have shed some light on this choice. Needless to say, the researcher opted for the easier route, which was to have him read first, as he then would have less of a chance of getting off-topic. That, in turn, would have meant lists in the proceeding stages that were irrelevant to the story read. Doing a study with more participants here too, would have given me options to do both.

It is believed that the most major flaw in planning this study is that it was only a longitudinal study of two sessions; which is almost a contradiction in itself. Had the researcher incorporated more than one student, data would have some measure of credibility. In this case, one person was chosen and he was only given two sessions in which to be observed. This is clearly not a valid means of conducting research in which data for any real conclusions to be drawn from. Although it casts a large shadow over the results, it was still a learning process for the beginning of further research on the topic since pre-writing planning is the most elemental and significant aspect of learning successful writing.

Lastly, it can be fairly explicated here that it is when a student begins to internalize what happened in a text, or in any kind of writing activity, that they can gain from a schemata accessing exercise. The process of C3 is not holistic language device and it is not complete. Rather it is one combination of exercises that are organized for use on specific skills directed at the task of preparing to write.

\section{ANALYSIS, CONCLUSION AND SUGGESTION}

Overall it can be said that there is no evidence that C3 had any effect whatsoever on Terry's writing, other than exposure to more meaningful chunks of language. It is nevertheless believed that the overwhelming lack of evidence for progression in quantity of writing is not simply that the strategies were ineffective. But there's more to it than that. Because the writing samples were so closely related in amount of words and sentences written, there must be more influencing his writing than what is easily seen from the pre- and post- writing samples. There are factors like familiarity of the reading material, time limits, and life issues that play a part in a student's motivation. A study conducted with more participants would have shed more light on this issue.

Although C3 has potential for further development, it gives a lot less qualifying information about the words than many writing strategies do. For example, it excuses pronunciation, words origins, and morphemes to name a few. It cannot, moreover, be articulated with surety whether those elements of language awareness are germane to pre-writing exercises, but nonetheless in so far as input is concerned, C3 is limited to the scope of words taken from a text and collocations. These are obviously not the only requisite tools for writing, and more instruction would definitely be required to groom an effective writer than just step-by-step process writing instruction.

Advanced students generally benefit more from text-driven vocabulary retention strategies than do beginners. This is partly due to a lack of ability to realize context for beginners, as they simply do not possess the vocabulary or decoding processes to infer much from a given text. Advanced learners however, can read supplemental information to further clarify or solidify what was considered previous knowledge. Ostensibly, one of the best things about pre-writing strategies is that it can be done individually. In this case, a text and a collocation dictionary are the only resources needed. Therefore, an advanced student could work productively by himself, as they already have schemata for approaching a writing activity. The challenge here, for the higher-level learner, would be to make appropriate judgments of what is or what is not topically relevant. A beginning language learner would on the other hand, have to wrestle with decoding the language in addition to any qualitative analysis of discourse. So the researcher would recommend that a process like this be utilized by learners who are above a beginning level of language proficiency.

\section{ACKNOWLEDGMENTS}

The author expresses his genuine appreciation to the Deanship of Scientific Research at King Saud University, and the Research Center at the College of Languages \& Translation for their candid support. 


\section{REFERENCES}

[1] Benson, Benson and Wilson. (1997). The BBI Dictionary of English Word Combinations. John Benjamins Publishing Company. Philadelphia.

[2] Bernardini, S. (2004). Corpora in the classroom: An overview and some reflections on future developments. In J. Sinclair (Ed.), How to use corpora in language teaching (pp.15-36). Amsterdam: Benjamins.

[3] Boulton, A. (2010). Data-driven learning: On paper, in practice. In T. Harris, \& M. Jaén (eds), Corpus linguistics in language teaching (pp.17-52). Frankfurt: Peter Lang.

[4] Carroll, M. and O. Mordaunt. (1991). 'The frontier method of vocabulary practice'. TESOL Journal 1/1: 23-6.

[5] Charles, M. (2007). Reconciling top-down and bottom-up approaches to graduate writing: Using a corpus to teach rhetorical functions. Journal of English for Academic Purposes, 6, 289-302.

[6] Gilmore, A. (2009). 'Using online corpora to develop students' writing skills'. ELT Journal, 63, 4, 363-372.

[7] Gitsaki, C. \& Taylor, P.R. (1997). English collocations and their place in the EFL classroom. Iranian Journal of Applied Linguistics, 6, 137-169.

[8] http://www.americanfolklore.net/folktales/ak.html. (accessed on 12/04/2012).

[9] http://www.americanfolklore.net/folktales/wv2.html. (accessed on 12/04/2012).

[10] http://www.eastoftheweb.com/short-stories/UBooks/Bull.shtml. (accessed on 12/04/2012).

[11] http://www.soon.org.uk/stories/the_match.htm. (accessed on 12/04/2012).

[12] Kennedy, C., \& Miceli, T. (2010). Corpus-assisted creative writing: Introducing intermediate Italian learners to a corpus as a reference resource. Language Learning \& Technology, 14(1), 28-44. Retrieved (01/12/2016) from http://llt.msu.edu/vol14num1/kennedymiceli.pdf.

[13] Lewis, Michael. (1997). "Pedagogical implications of the lexical approach." In: Coady, J. and Huckin, T. Second Language Vocabulary Acquisition. Cambridge University Press.

[14] Lewis, Michael. (2000). Learning in the lexical approach. In M. Lewis (Ed.), Teaching collocation: Further developments in the lexical approach (pp. 155-185). Hove, UK: Language Teaching Publications.

[15] Mukherjee, J. (2006). Corpus linguistics and language pedagogy: The state of the art - and beyond. In S. Braun, K. Kohn \& J. Mukherjee (Eds.), Corpus Technology and Language Pedagogy (pp.5-24). Frankfurt am Main: Peter Lang.

[16] Sinclair, J. (2004). How to use corpora in language teaching. Amsterdam, The Netherlands: John Benjamins.

[17] Sökman, A. J. (1992). "Students as vocabulary generators." TESOL Journal. 1:4. Summer. 16-18.

[18] Yoon, Hyunsook and Jo, Jung Won. (February, 2014). Direct and Indirect Access to Corpora: An Exploratory Case Study Comparing Students' error correction and learning strategy use in L2 Writing. In Language Learning \& Technology, Volume 18, Number 1 pp. 96-117.

[19] Yoon, H., \& Hirvela, A. (2004). ESL students toward corpus use in L2 writing. Journal of Second Language Writing, 13, 257283.

Mubarak Alkhatnai is an assistant professor of applied linguistics and TESOL at King Saud University. He has been taught in the USA, UK and Canada. His research interests include, but not limited to, computer assisted language learning, ELT and tran slation. 